\title{
Point-of-care, peer-comparator colonoscopy practice audit: The Canadian Association of Gastroenterology Quality Program - Endoscopy
}

\author{
David Armstrong MA MB BChir FRCPC FRCP(UK) ${ }^{1}$, Roger Hollingworth MD FRCPC ${ }^{2}$, \\ Donald MacIntosh MD MSc FRCPC ${ }^{3}$, Ying Chen MSc ${ }^{1}$, Sandra Daniels MSc ${ }^{4}$, Stuart Gittens BSc ${ }^{5}$, \\ Ron Bridges MD FRCPC ${ }^{6}$, Paul Sinclair MSC ${ }^{4}$, Catherine Dubé MD MSc FRCPC ${ }^{6}$
}

D Armstrong, R Hollingworth, D MacIntosh, et al. Point-of-care, peer-comparator colonoscopy practice audit: The Canadian Association of Gastroenterology Quality Program - Endoscopy. Can J Gastroenterol 2011;25(1):13-20.

BACKGROUND: Point-of-care practice audits allow documentation of procedural outcomes to support quality improvement in endoscopic practice.

OBJECTIVE: To evaluate a colonoscopists' practice audit tool that provides point-of-care data collection and peer-comparator feedback. METHODS: A prospective, observational colonoscopy practice audit was conducted in academic and community endoscopy units for unselected patients undergoing colonoscopy. Anonymized colonoscopist, patient and practice data were collected using touchscreen smartphones with automated data upload for data analysis and review by participants. The main outcome measures were the following colonoscopy quality indicators: colonoscope insertion and withdrawal times, bowel preparation quality, sedation, immediate complications and polypectomy, and biopsy rates.

RESULTS: Over a span of 16 months, 62 endoscopists reported on 1279 colonoscopy procedures. The mean cecal intubation rate was $94.9 \%$ (10th centile $84.2 \%$ ). The mean withdrawal time was $8.8 \mathrm{~min}$ and, for nonpolypectomy colonoscopies, $41.9 \%$ of colonoscopists reported a mean withdrawal time of less than 6 min. Polypectomy was performed in $37 \%$ of colonoscopies. Independent predictors of polypectomy included the following: endoscopy unit type, patient age, interval since previous colonoscopy, bowel preparation quality, stable inflammatory bowel disease, previous colon polyps and withdrawal time. Withdrawal times of less than 6 min were associated with lower polyp removal rates (mean difference $-11.3 \%$ [95\% CI $-2.8 \%$ to $-19.9 \%] ; \mathrm{P}=0.01$ ).

DISCUSSION: Cecal intubation rates exceeded $90 \%$ and polypectomy rates exceeded $30 \%$, but withdrawal times were frequently shorter than recommended. There are marked practice variations consistent with previous observations.

CONCLUSION: Real-time, point-of-care practice audits with prompt, confidential access to outcome data provide a basis for targeted educational programs to improve quality in colonoscopy practice.

Key Words: Colonoscopy; Health care; Practice audit; Quality assurance; Quality indicators

$\mathrm{T}_{\mathrm{h}}^{\mathrm{h}}$ he advent of colon cancer screening has prompted many organizations (1-6) to identify specific colonoscopy quality indicators (such as appropriate surveillance interval, cecal intubation rate, adenoma detection rate, colonoscope withdrawal time, quality of colon preparation, sedation and assistants' experience) that are considered to be clinically relevant
La vérification de la pratique de coloscopie au chevet du patient en comparaison avec les collègues : le programme de qualité de l'endoscopie en gastroentérologie de l'Association canadienne de gastroentérologie

HISTORIQUE : Les vérifications de la pratique au chevet du patient permettent de consigner l'issue de l'intervention afin de favoriser l'amélioration de la qualité en endoscopie.

OBJECTIF : Évaluer l'outil de vérification de la pratique d'un coloscopiste qui permet de colliger les données au chevet du patient et d'obtenir des comparatifs avec les collègues.

MÉTHODOLOGIE : Les chercheurs ont procédé à la vérification prospective et par observation de la pratique de coloscopie dans des unités d'endoscopie universitaires et communautaires auprès de patients non sélectionnés qui subissaient une coloscopie. Ils ont colligé des données anonymisées sur le coloscopiste, le patient et la pratique au moyen de téléphones tactiles intelligents dotés d'un téléchargement automatisé des données en vue de leur analyse et de leur examen par les participants. Les principales mesures d'issue étaient constituées des indicateurs de qualité suivants de la coloscopie : durée d'insertion et de retrait du coloscope, qualité de la préparation intestinale, sédation, complications immédiates, taux de polypectomies et de biopsies.

RÉSULTATS : En l'espace de 20 mois, 62 coloscopistes ont fait le compte rendu de 1279 coloscopies. Le taux d'intubation cæcale moyen était de $94,9 \%$ ( $10^{\mathrm{e}}$ centile $84,2 \%$ ). Le taux de retrait moyen était de 8,8 minutes et, dans le cas des coloscopies sans polypectomies, 41,9\% des coloscopistes déclaraient un taux de retrait moyen de moins de 6 minutes. Des polypectomies accompagnaient $37 \%$ des coloscopies. Les prédicteurs indépendants de polypectomie incluaient le type d'unité d'endoscopie, l'âge du patient, l'intervalle depuis la coloscopie précédente, la qualité de la préparation intestinale, une maladie inflammatoire de l'intestin stable, des polypes antérieurs du côlon et le délai de retrait. Un délai de retrait de moins de 6 minutes s'associait à un taux de retrait de polypes moins élevé (différence moyenne -11,3 \% [95 \% IC -2,8 \% à -19,9\%]; P=0,01).

EXPOSÉ : Les taux d'intubation cæcale étaient supérieurs à $90 \%$ et les taux de polypectomie, supérieurs à $30 \%$, mais les délais de retrait étaient souvent plus courts que ne l'indiquent les recommandations. Conformément aux observations antérieures, on constate des variations marquées de la pratique. CONCLUSION : La vérification de la pratique de coloscopie au chevet du patient en temps réel assurant un accès confidentiel et rapide aux données d'issues fournissait des assises pour donner des programmes de formation ciblée en vue d'améliorer la qualité des pratiques de coloscopie.

(7-11) and easily measurable $(5,6)$. Quality improvement requires these indicators to be measured and linked to educational interventions that enable individual endoscopists or institutions to correct identified deficiencies.

Recognizing the critical importance of quality outcomes for endoscopy, the Canadian Association of Gastroenterology

${ }^{1}$ Division of Gastroenterology, McMaster University, Hamilton; ${ }^{2}$ Division of Gastroenterology, The Credit Valley Hospital, Mississauga, Ontario;

${ }^{3}$ Division of Gastroenterology, Dalhousie University, Halifax, Nova Scotia; ${ }^{4}$ Canadian Association of Gastroenterology, Oakville, Ontario;

${ }^{5}$ ECD Solutions, Atlanta, Georgia, USA; ${ }^{6}$ Division of Gastroenterology, University of Calgary, Calgary, Alberta

Correspondence: Dr David Armstrong, HSC-4W8F, Division of Gastroenterology, McMaster University Medical Centre, 1200 Main Street West,

Hamilton, Ontario L8N 325. Telephone 905-521-2100 ext 76404, fax 905-521-4958, e-mail armstro@mcmaster.ca

Received for publication November 20, 2010. Accepted November 22, 2010 


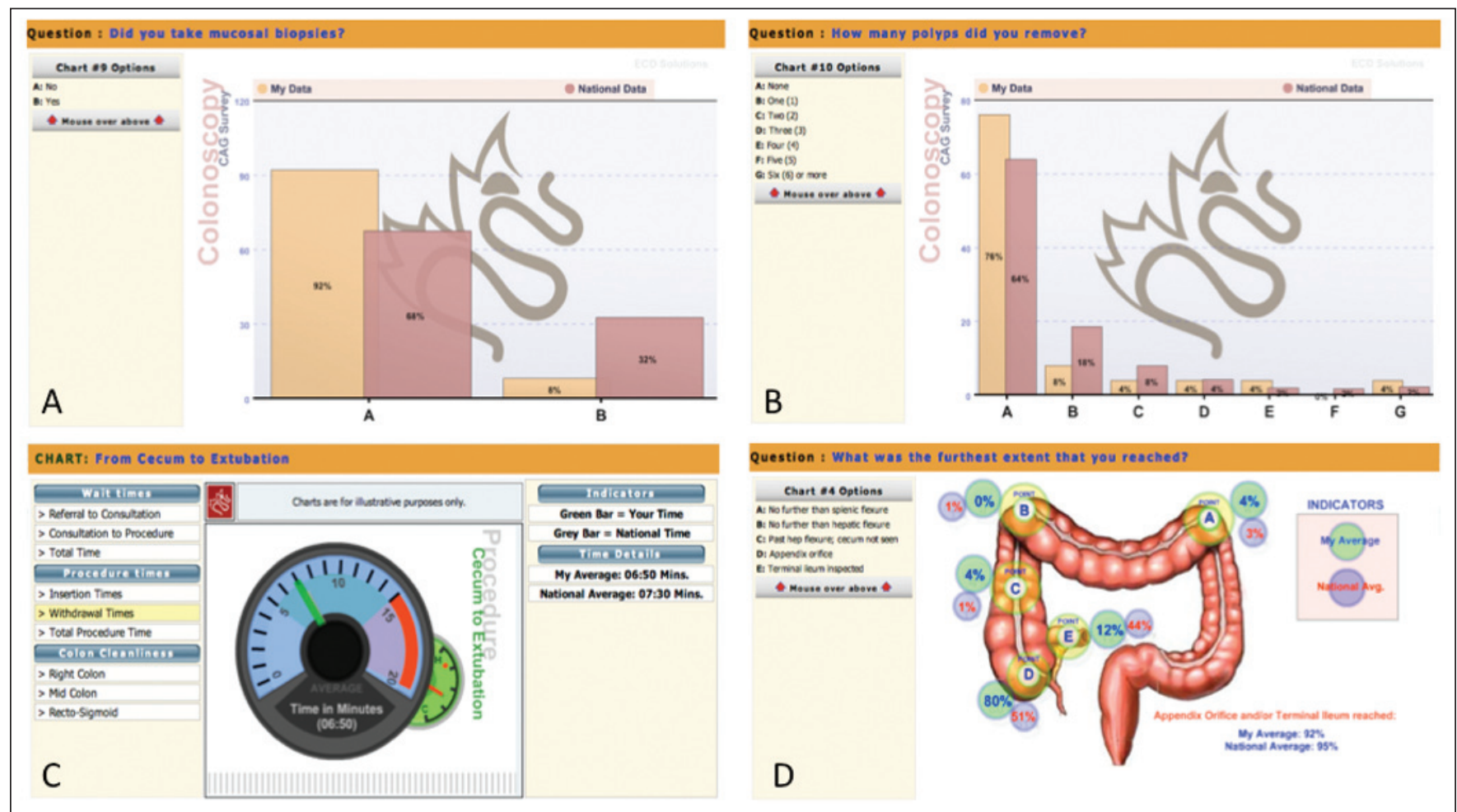

Figure 1) Screenshots from the Canadian Association of Gastroenterology colonoscopy practice audit website showing sample comparisons of a individual's data (simulated) compared with aggregate national data (real) for mucosal biopsy rates (\% of colonoscopies) (A), the number of polyps removed (\% of colonoscopies) (B), withdrawal time ( $\mathrm{min})(\mathrm{C})$ and the furthest extent of the colonoscopy examination (\% of examinations) (D)

(CAG) developed credentialing guidelines $(6,12)$ and practice audit methods (13-15) to support quality improvement in clinical endoscopic practice.

The aims of the present study were to audit colonoscopists' practice using a novel, point-of-care data collection method and to compare the results with those of a previous practice audit program (13). Prompt, anonymous, peer-comparator feedback would then enable the identification of practice gaps, the provision of targeted educational programs and subsequent re-evaluation of endoscopic practice.

\section{METHODS}

A steering committee with expertise in practice audit and quality programs oversaw the project with respect to concept development, practice audit logistics management, data reporting and data analysis. No patient identifiers were required (13-15); therefore, the study was deemed to be a quality assurance program and, thus, did not require formal research ethics board approval.

\section{Participants}

Endoscopists at 19 Canadian centres audited colonoscopies over periods of at least two weeks using data collection software on a touch-screen smartphone (Treo 650, Palm Inc, Canada) linked to a secure website (ReForm XT, Goanyware Software, USA). The smartphones displayed only one question per screen and, in most cases, all text was visible without scrolling. After confirmed completion of data entry for each patient, data were saved and uploaded immediately if network access was available; otherwise, data were uploaded automatically when network access was re-established.

After descriptive analysis and verification, summary data were displayed at a password-protected website (ECD Solutions,
USA) enabling participants to compare their data with other participants' aggregate data (Figure 1). The start and end times of each participant's website access, and the pages visited were tracked. Participants could download a record of accredited educational hours spent evaluating or reflecting on their audit (16).

\section{Data collection}

Participants' baseline personal data including age, practice type and years in practice (Table 1) were entered only once and linked to all subsequent practice audit data. Participants were required to answer all questions on a 'screen' before advancing; they could only select one answer for a question unless it had been marked as 'select all that apply'.

Practice audit data could be collected only at the time of the procedure; anonymized data were collected on the reason for colonoscopy ('investigation of abnormality', 'screening' or 'surveillance'), specific indications, the time elapsed since referral and consultation ('wait times'), the duration of the procedure, preparation quality (using the Ottawa bowel preparation scale [17]), sedation and any interventions (Table 2). For procedure times, participants or an assistant tapped the touch screen to indicate the time when the following occurred: the colonoscope entered the rectum; the cecum (or furthest point in the colon) was reached; withdrawal was started; and the colonoscope was withdrawn completely.

\section{Data analysis}

Uploaded data were reviewed for validity and plausibility. Invalid data included the following: insertion or withdrawal times of less than $30 \mathrm{~s}$; wait times from referral or consultation if the consultation date preceded the referral date, if the 
TABLE 1

\section{Participant demographic data (entered only once for each} participant)

1. Please enter your ID number

2. Primary ( $>50 \%$ of your practice) specialty/subspecialty

$\square$ Gastroenterology

$\square$ Surgery

$\square$ Other

3. Office details - You practice in a:

University full-time practice

- University part-time, private practice part-time

Private clinic practice

4. Is this an independent or group practice?

$\square$ Independent

Group

5. Endoscopy/colonoscopy suite details (check all that apply):

口 Community hospital

- University/teaching hospital

$\square$ Private clinic

6. Gender

$\square$ Male

$\square$ Female

7. Years in specialist practice

- Less than 2

口 2-5

ㅁ 6-10

11-20

口 21-30

More than 30

D N/A

N/A Not applicable

procedure date preceded the consultation or referral dates, or if the referral or consultation dates were 'out of range'. 'Out of range' dates occurred when the default date (procedure date) had not been reset or had been entered as '1999' because the referral or consultation dates were unavailable.

Results were presented as mean or median values with 95\% CIs or 10 th, 25 th and 75 th centile values, as appropriate. Multivariate logistic regression analysis (SAS version 9.2, SAS Institute Inc, USA) identified independent predictors of colonoscopy withdrawal times (using logarithmic transforms of withdrawal times) and polyp removal rates. Results were presented as the least squares means of withdrawal times (including 95\% CIs); polyp removal (none versus one or more) was used as the response for multiple logistic regression analysis. Multiple comparison adjustment was applied for all pair-wise comparisons.

\section{Demographics}

\section{RESULTS}

From February 2008 to June 2009, 62 endoscopists (Nova Scotia [n=5], Quebec [n=6], Ontario [n=21], Manitoba [n=4], Saskatchewan [n=14], Alberta [n=9] and British Columbia $[n=3] ; 46$ gastroenterologists and 16 surgeons) from 19 centres audited 1279 colonoscopy procedures (mean 20.6 procedures per participant). More participants $(69.4 \%)$ practised in an

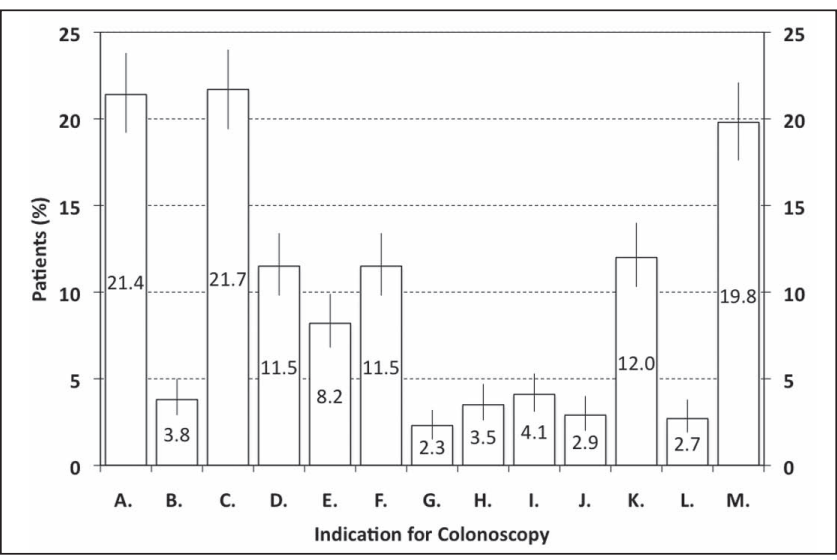

Figure 2) Indications for procedures $(n=1279)$. Data are shown as percentage of procedures (95\% CIs) for each indication. Some procedures were performed for more than one indication. A Gastrointestinal blood loss/anemia; B Positive fecal occult blood test; C Family history of colon cancer (first-degree relative); D Diarrhea; E Constipation; F Abdominal pain; G Unexplained weight loss; $\mathrm{H}$ Exacerbation of inflammatory bowel disease; I Stable inflammatory bowel disease for more than 10 years; J Previous colon cancer; K Previous colon polyps; L Abnormality on another test (double-contrast barium enema, computed tomography scan, etc); $\mathrm{M}$ Other

academic- versus a community-based hospital setting (30.6\%); $9.7 \%$ of participants also practised in another setting (eg, a private out-of-hospital clinic). Participants' experience (ie, years in practice) was recorded as less than five years $(29.0 \%)$, six to 10 years $(16.1 \%), 11$ to 20 years $(35.5 \%)$ and more than 20 years $(17.7 \%)$. Data regarding insertion times were invalid for 55 procedures $(4.3 \%)$ and on wait times from referral for 88 procedures $(6.9 \%)$. Patients' age ranged from 18 to 40 years $(9.8 \%), 41$ to 50 years $(16.7 \%), 51$ to 60 years $(31.5 \%)$ and 61 to 70 years $(24.9 \%)$, to older than 70 years of age $(17.0 \%)$. The most common indications (Figure 2) were a family history of colon cancer $(21.7 \%)$ and a history of gastrointestinal blood loss or anemia (21.4\%); a positive fecal occult blood test was the indication for only 3.8\% of procedures. Overall, 577 procedures (45.1\%) were performed for the investigation of abnormal symptoms and/or signs, or previous test abnormalities, 475 (37.1\%) for colon cancer screening and 227 (17.7\%) for surveillance.

Most patients received sedation: $96.5 \%$ received a benzodiazepine with or without an opiate, while $2.0 \%$ received propofol and $1.5 \%$ received no sedation. Bowel preparation was excellent (Ottawa bowel scale score of less than 5) in $75.6 \%$ of cases. Immediate complications were reported for nine cases $(0.7 \%)$ including respiratory problems $(n=4)$, bleeding $(n=3)$, perforation $(n=1)$ and cardiac problems $(n=1)$.

\section{Cecal and ileal intubation}

The mean intubation rate for the cecum or ileum was $94.9 \%$ (median 97.5\%), and 43.3\% (43.4\%) for the ileum. Mean cecal intubation rates ranged from $93.5 \%$ (investigation of abnormality) and $95.5 \%$ (screening) to $96.6 \%$ (surveillance). The 10 th centile for cecal intubation was $84.2 \%$ (ie, $10 \%$ of participants had a mean cecal intubation rate below $85 \%$ ), ranging from $78.9 \%$ (investigation of abnormality) and $90.9 \%$ (screening) to $83.3 \%$ (surveillance). Mean ileal intubation 


\section{TABLE 2}

\section{Colonoscopy procedure data (entered in real time during} each procedure)

1. When was this patient FIRST referred to you (when was your office FIRST contacted by any means such as phone, fax, etc)?

2. When did you have the consultation with the patient related to this colonoscopy?

3. Patient's age

口 18-40 years

- 41-50 years

- 51-60 years

口 61-70 years

$\square>70$ years

4. What is the reason for this colonoscopy?

$\square$ Investigation of symptoms or abnormal findings

- Screening

- Surveillance

5. What were the specific indications for this colonoscopy? (Check all that apply)

Evidence of GI tract blood loss (including anemia)

Positive FOBT

Family history of colon cancer (first-degree relative)

$\square$ Diarrhoea

- Constipation

abdominal pain

$\square$ Unexplained weight loss

Exacerbation of inflammatory bowel disease

- Stable inflammatory bowel disease $>10$ years

P Previous colon cancer

- Previous colon polyps

Abnormality on other investigation (DCBE, CT)

O Other

6. When was this patient's last colonoscopy?

$\square$ Never

$\square<1$ year ago

口 1-2 years ago

口 2-5 years ago

-5-10 years ago

$\square>10$ years ago

Procedural times

7. To time stamp START of colonoscopy, tap advance arrow

8. To time stamp reaching cecum or furthest extent of examination, tap advance arrow

9. To time stamp start of scope withdrawal, tap advance arrow

10. To time stamp completion of colonoscopy, tap advance arrow

11. What was the furthest extent that you reached? (Check only one)

- No further than splenic flexure <program skips to Q\#15>

- No further than hepatic flexure <program skips to Q\#14>

- Past hepatic flexure; cecum not seen

appendiceal orifice \& ileocecal valve seen

$\square$ Terminal ileum inspected

Ottawa Bowel Preparation Scale

12. Fluid in whole colon:

口 Small

․ Moderate

- Large

Not applicable

13. Cleanliness of the RIGHT colon

Excellent: Mucosal detail visible, no/clear fluid, almost no stool.

Good: Turbid fluid/stool but mucosa visible, wash/suction not needed.

Fair: Fluid/stool obscuring mucosa, seen with suction, wash not needed.
Poor: Stool obscures, OK view with suction/wash

- Inadequate: Stool obscures despite major wash/suction

14. Cleanliness of the MID colon

Excellent: mucosal detail visible, no/clear fluid, almost no stool

Good: Turbid fluid/stool but mucosa visible, wash/suction not needed

Fair: Fluid/stool obscuring mucosa, seen with suction, wash not needed

Poor: Stool obscures, OK view with suction/wash

- Inadequate: Stool obscures despite major wash/suction

15. Cleanliness of the RECTO-SIGMOID colon

- Excellent: Mucosal detail visible, no/clear fluid, almost no stool

Good: Turbid fluid/stool but mucosa visible, wash/suction not needed

Fair: Fluid/stool obscuring mucosa, seen w suction, wash not needed

- Poor: Stool obscures, OK view with suction/wash

- Inadequate: Stool obscures despite major wash/suction

Procedural details

16. Did you take mucosal biopsies?

$\square$ No

口 Yes

17. How many polyps did you remove?

$\square$ None

口 1

口 2

口 3

口 4

口 5

- 6 or more

18. Did any complications occur during the colonoscopy? (Check all that apply)

No complications

- Yes - bleeding

- Yes - perforation

- Yes - respiratory problems

- Yes - cardiac problems

19. What medications were administered? (Check all that apply)

ㄱone

- Benzodiazepine (eg, diazepam, midazolam)

口 Opiate (eg, meperidine, fentanyl)

- Antispasmodic (eg, hyoscine butylbromide)

口 Propofol

$\square$ Other

CT Computed tomography; DCBE Double-contrast barium enema; FOBT Fecal occult blood test; GI Gastrointestinal

rates varied among provinces (Figure 3 ) but not with respect to the reason for colonoscopy (data not shown).

Withdrawal times

Overall, the mean withdrawal time was 8.8 min (median $7.9 \mathrm{~min}$ ); mean withdrawal times were longer for patients who underwent polypectomy ( $12.0 \mathrm{~min}$; median $10.9 \mathrm{~min}$ ) than for those who did not ( $6.8 \mathrm{~min}$; median $6.3 \mathrm{~min})$. For nonpolypectomy procedures, 26 participants $(41.9 \%)$ recorded a mean withdrawal time of less than $6 \mathrm{~min}$; in the same procedures, the median of the mean withdrawal times was 6.3 min (Figure 4) and the 10th centile was $4.0 \mathrm{~min}$ (ie, $10 \%$ of participants reported a mean withdrawal time of 4 min or less).

Multiple logistic regression analysis (1185 colonoscopies with valid data) identified eight variables associated with a difference in withdrawal time (Table 3): the reason for 


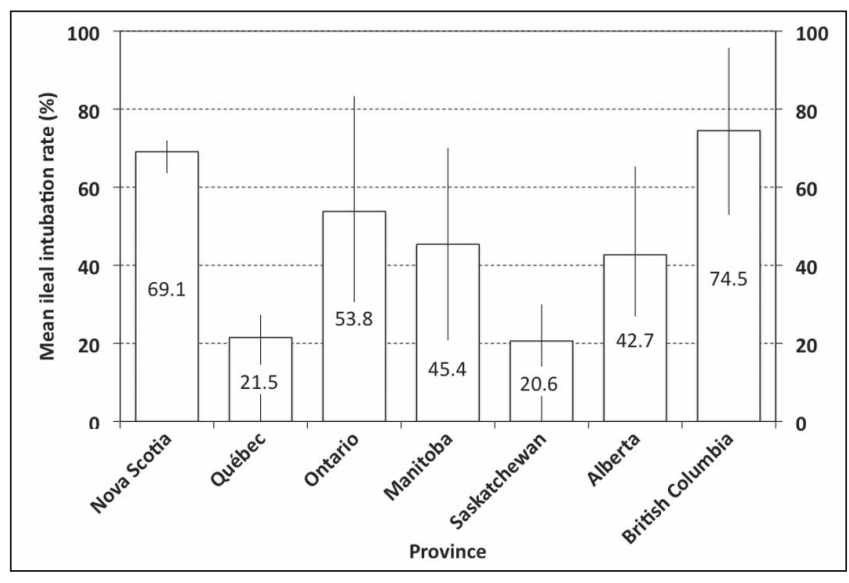

Figure 3) Ileal intubation rates per participant (mean \%, error bars indicate 25 th and 75 th centiles) according to province for all indications

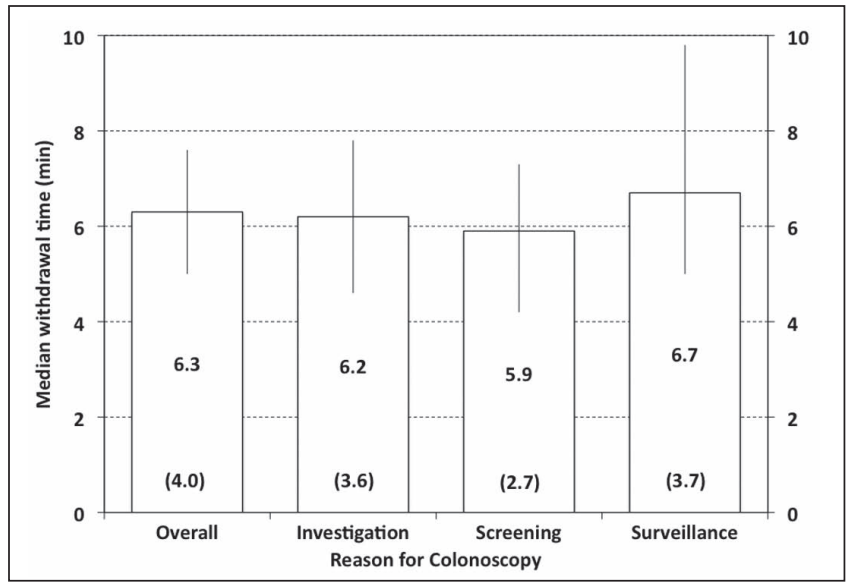

Figure 4) Mean withdrawal times per participant are summarized for all procedures (overall) and according to reason for colonoscopy (columns indicate median times, error bars indicate 25th and 75 th centiles, numbers in brackets indicate 10th centiles for each group)

colonoscopy $(\mathrm{P}<0.0001)$, years in specialist practice $(\mathrm{P}=0.0002)$, patient age $(\mathrm{P}=0.0317)$, bowel preparation quality $(\mathrm{P}<0.0001)$, propofol sedation $(\mathrm{P}=0.0358)$, furthest extent of examination $(\mathrm{P}<0.0001)$, the number of polyps removed $(\mathrm{P}<0.0001)$ and stable inflammatory bowel disease (IBD) $(\mathrm{P}=0.0492)$. In addition, there were five significant interaction effects: years in specialist practice according to reason for colonoscopy $(\mathrm{P}=0.0088)$; reason for colonoscopy according to stable IBD $(\mathrm{P}<0.0001)$; preparation quality according to propofol sedation $(\mathrm{P}=0.0135)$; furthest extent of examination according to biopsies taken $(\mathrm{P}=0.0023)$; and the number of polyps removed according to biopsies taken $(\mathrm{P}<0.0001)$.

\section{Polypectomy rates}

Overall, the mean percentage of colonoscopies performed by each endoscopist involving one or more polypectomies was $37.0 \%$ (median $34.0 \%$ ) (Figure 4 ), and the mean number of polypectomies was 0.9 (median 0.7 ) for all procedures and 2.2 (median 2.0) for procedures in which at least one polyp was removed. However, $10 \%$ of participants reported polypectomy in $13.3 \%$ or fewer of their colonoscopies (Figure 5). Multiple logistic regression analysis (1177 colonoscopies with valid
TABLE 3

Variables associated with differences in colonoscope withdrawal time

\begin{tabular}{|c|c|c|c|}
\hline \multirow[b]{2}{*}{ Variable } & \multirow[b]{2}{*}{$\mathbf{n}$} & \multicolumn{2}{|c|}{ Withdrawal time, min } \\
\hline & & Mean & $95 \% \mathrm{Cl}$ \\
\hline \multicolumn{4}{|l|}{ Reason for colonoscopy } \\
\hline Investigation & 525 & 11.4 & $9.1-14.1$ \\
\hline Screening & 446 & 4.6 & $3.3-6.6$ \\
\hline Surveillance & 214 & 11.6 & $10.0-13.9$ \\
\hline \multicolumn{4}{|l|}{ Years in specialist practice } \\
\hline$\leq 5$ & 218 & 9.6 & 8.0-11.6 \\
\hline 6 to 10 & 238 & 7.8 & $6.5-9.4$ \\
\hline 11 to 20 & 490 & 8.1 & $6.8-9.7$ \\
\hline$>20$ & 239 & 8.7 & $7.2-10.3$ \\
\hline \multicolumn{4}{|l|}{ Patient age, years } \\
\hline $18-40$ & 117 & 7.8 & $6.5-9.5$ \\
\hline $41-50$ & 202 & 9.2 & $7.7-11.1$ \\
\hline $51-60$ & 377 & 8.5 & 7.1-10.2 \\
\hline $61-70$ & 294 & 8.4 & 7.0-10.0 \\
\hline$>70$ & 195 & 8.8 & 7.3-10.6 \\
\hline \multicolumn{4}{|c|}{ Bowel preparation quality (Ottawa scale score) } \\
\hline Excellent $(\leq 5)$ & 896 & 6.6 & $5.6-7.9$ \\
\hline Not excellent $(>5)$ & 289 & 11.0 & $8.7-13.6$ \\
\hline \multicolumn{4}{|l|}{ Sedation } \\
\hline No sedation & 18 & 10.1 & $7.8-13.2$ \\
\hline Benzodiazepine and/or opiate & 1143 & 9.0 & 7.6-10.4 \\
\hline Propofol & 24 & 6.9 & $5.3-8.9$ \\
\hline \multicolumn{4}{|l|}{ Extent of colonoscopy } \\
\hline Cecum not intubated & 24 & 7.9 & $6.1-10.2$ \\
\hline Cecum but not ileum intubated & 624 & 8.2 & $6.9-9.8$ \\
\hline Ileum intubated & 537 & 9.6 & $8.0-11.4$ \\
\hline \multicolumn{4}{|l|}{ Polyps removed, $\mathrm{n}$} \\
\hline 0 & 749 & 5.1 & $4.3-6.0$ \\
\hline 1 & 222 & 6.9 & $5.8-8.3$ \\
\hline 2 & 92 & 8.6 & $7.2-10.6$ \\
\hline 3 & 51 & 8.7 & $7.1-10.8$ \\
\hline 4 & 22 & 10.0 & $7.7-13.0$ \\
\hline 5 & 19 & 11.6 & 8.9-15.2 \\
\hline$\geq 6$ & 30 & 10.5 & 8.3-13.5 \\
\hline \multicolumn{4}{|l|}{ Stable inflammatory bowel disease } \\
\hline Yes & 48 & 7.5 & $5.7-9.9$ \\
\hline Other patients & 1137 & 9.7 & 8.5-11.2 \\
\hline
\end{tabular}

data) identified the following seven variables that were significantly associated with differences in polypectomy rates (Table 4): centre type $(\mathrm{P}<0.004)$, patient age $(\mathrm{P}<0.0001)$, interval since most recent colonoscopy $(\mathrm{P}<0.0001)$, bowel preparation quality $(\mathrm{P}<0.02)$, stable IBD $(\mathrm{P}<0.02)$, history of previous colon polyps $(\mathrm{P}<0.0001)$ and shorter withdrawal times $(\mathrm{P}<0.0001)$. In addition, there was one significant interaction effect: withdrawal time according to family history of colon cancer $(\mathrm{P}<0.004)$. For patients with a family history of colon cancer, the OR for polypectomy was 1.536 (95\% CI 1.348 to 1.749$)$ per $1 \mathrm{~min}$ increase in withdrawal time while, for those with no family history, the OR was 1.257 (95\% CI 1.204 to 1.312 ).

More prolonged withdrawal times for nonpolypectomy procedures were associated with polypectomy in a greater proportion of colonoscopies (Figure 6). Participants $(n=26)$ who had a mean $( \pm \mathrm{SD})$ withdrawal time of shorter than $6 \mathrm{~min}(4.57 \pm 1.27 \mathrm{~min})$ 


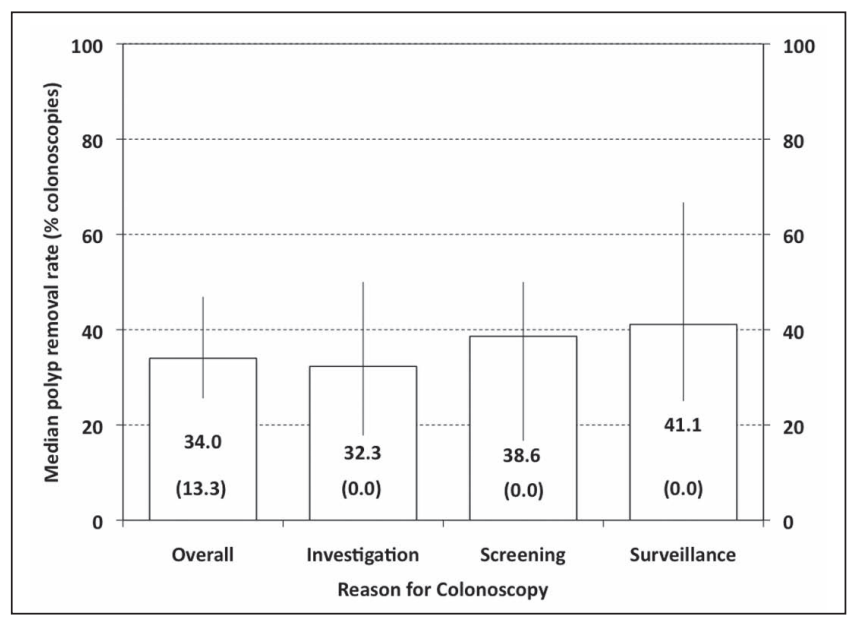

Figure 5) Mean polypectomy rates per participant are summarized for all procedures (overall) and according to reason for colonoscopy (columns indicate median rates, error bars indicate 25 th and 75 th centiles, numbers in brackets indicate 10th centiles for each group)

TABLE 4

Variables associated with differences in polyp removal rate

\begin{tabular}{lll}
\hline Variable & $\mathrm{OR}^{*}$ & $95 \% \mathrm{Cl}$ \\
\hline
\end{tabular}

Centre type

Community versus academic practice $\quad 0.5420 \quad 0.3438-0.8545$

Patient age, years

$\begin{array}{lll}18 \text { to } 40 \text { versus }>70 & 0.2761 & 0.1134-0.6717 \\ 41 \text { to } 50 \text { versus }>70 & 0.2828 & 0.1343-0.5957 \\ 51 \text { to } 60 \text { versus }>70 & 0.6429 & 0.3518-1.1748 \\ 61 \text { to } 70 \text { versus }>70 & 0.9540 & 0.5110-1.7812\end{array}$

Interval since most recent colonoscopy, years

$\begin{array}{lll}\text { Never versus }<1 & 2.6378 & 0.6593-10.5544 \\ \text { Never versus } 1 \text { to } 2 & 1.3619 & 0.5391-3.4406 \\ \text { Never versus } 3 \text { to } 5 & 3.0173 & 1.4708-6.1900 \\ \text { Never versus } 6 \text { to } 10 & 2.2381 & 1.1092-4.5158 \\ \text { Never versus }>10 & 1.5641 & 0.4175-5.8597\end{array}$

Bowel preparation quality (Ottawa scale score)

Excellent $(\leq 5)$ versus not excellent $(>5) \quad 1.5583 \quad 1.1057-2.1961$

Stable IBD

Stable IBD versus others $\quad 3.1183 \quad 1.2271-7.9244$

Previous colon polyps

No polyps versus previous polyps $\quad 0.2089 \quad 0.1275-0.3424$

${ }^{*}$ ORs of less than 1.0 indicate a lower probability of polyp removal. IBD Inflammatory bowel disease

for procedures when they did not remove a polyp had a lower polyp removal rate $(29.3 \pm 17.3 \%$ versus $40.7 \pm 15.9 \% ; \mathrm{P}=0.01$; mean difference $-11.3 \%$ [95\% CI -2.8 to $-19.9 \%]$ ) than participants $(n=35)$ who had a mean withdrawal time of 6 min or longer $(8.43 \pm 3.24 \mathrm{~min})$ for nonpolypectomy procedures.

\section{Mucosal biopsy rates}

The overall mucosal biopsy rate (32.4\%) did not differ with respect to polypectomy, but was markedly lower for screening colonoscopies than for colonoscopies investigating abnormal signs or symptoms, or for surveillance (Figure 7).

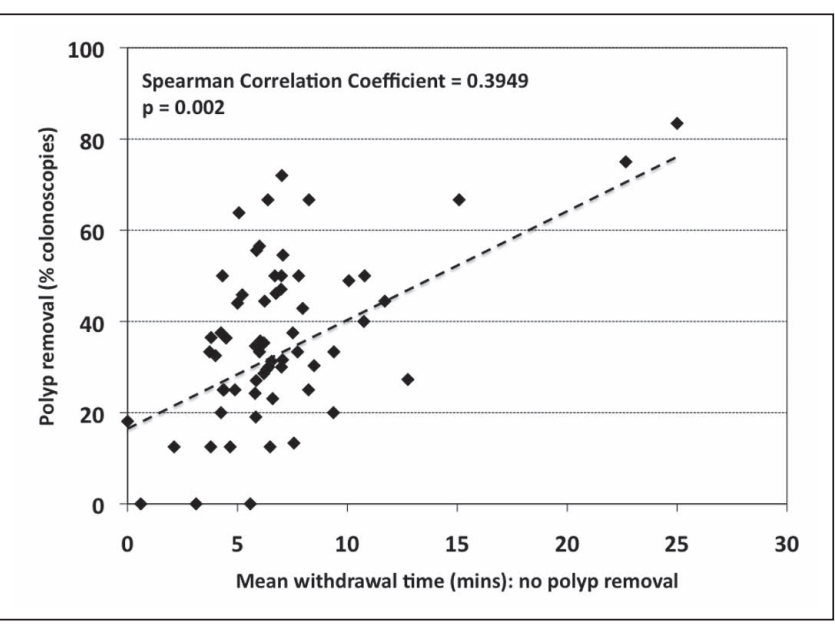

Figure 6) Relationship between polypectomy rate (\% colonoscopies) and mean withdrawal time for colonoscopies during which no polyp was removed, for all participants $(n=61)$

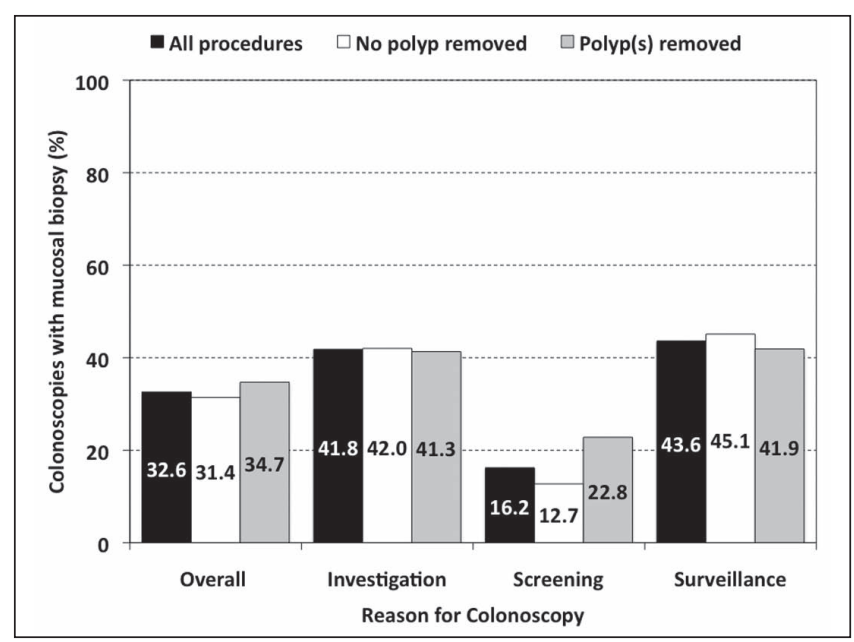

Figure 7) Proportion of colonoscopies at which a mucosal biopsy was taken, presented for all procedures (overall) and according to reason for colonoscopy. Data are shown for all procedures in each group (black bars), and for those in which polyps were (grey bars) and were not (white bars) removed

\section{DISCUSSION}

The present prospective, multicentre, national program demonstrated the feasibility of point-of-care practice audit (13), and provided baseline data on widely endorsed colonoscopy quality indicators (2-6). These data will support repeat peercomparator programs for quality improvement in gastroenterology and endoscopy allied to personal continuing professional development. The current study was smaller than the earlier study (13); however, it represented approximately 5\% of practising Canadian endoscopists (18). The higher proportion of screening colonoscopies in the current study (37\% versus $25 \%$ [13]) was probably due to the increase in colorectal cancer screening across Canada.

These results identify several indicators that are amenable to intervention and improvement. Only $73 \%$ of bowel preparations were rated as excellent (17), indicating the need for improved bowel preparation strategies. The mean cecal intubation rate $(94.9 \%)$ increased slightly from 92\% (13) but, 
although it appears acceptable (2-4), 10\% of participants reported a mean rate of less than $85 \%$. Ileal intubation rates were higher $(43.3 \%)$ than previously reported (29.1\% [13]) but, unlike mucosal biopsy rates, provincial variations did not appear to be related to the reason for colonoscopy.

The mean withdrawal time of 8.8 min exceeded recommendations (longer than 6 min [8,9]), but $38.7 \%$ of participants reported shorter withdrawal times for procedures during which they did not remove polyps and this was associated, as in previous studies (8), with lower polypectomy rates. Polypectomy, rather than adenoma confirmation or polyp detection, was used as an outcome measure to ensure documentation of clinically relevant lesions while avoiding delays needed to assure adenoma confirmation; the reported rates suggest that polypectomy is comparable with these other measures as a surrogate end point.

The nonlinear relationship between experience and withdrawal time suggests a complex interaction among clinical judgment, technical expertise and practice pressures that may be difficult to modify. Other predictors of withdrawal time, such as the choice of bowel preparation and sedation, are modifiable and should respond to an educational intervention. The identification of outcome predictors does not confirm a causal relationship, but it may indicate why practice and outcomes differ with respect to centre type, colonoscopy indication, bowel preparation adequacy and withdrawal time.

The results of the present study are open to bias because the procedures were selected by the participant and the data were self-reported. However, the outcome of the procedure was unknown when data entry began, thus limiting the participant's ability to select favourable cases. Bias arising from self-reporting was, perhaps, lessened because data were known to be confidential; additionally, in many cases, procedural data were recorded or confirmed by an endoscopy nurse to reduce the risk of bias.

Ideally, practice audits should include data on delayed adverse events and adenoma detection rates; however, this would have required delayed data entry, including patient identifiers, which is incompatible with point-of-care data collection. Data from national registries such as the Clinical Outcomes Research Initiative (USA) (19) suggest that 30-day complication rates for screening and surveillance colonoscopy are very low (20); thus, the reporting requirements for delayed events are inconsistent with the present type of practice audit.

The strengths of the reported methodology are its rapidity, simplicity and ability to collect real-time data with low infrastructure costs. The questionnaire content and format were managed entirely by the investigators and the cost per completed questionnaire was less than US\$1.00 (ReForm XT, GoAnyWare Solutions, USA). Questionnaire data were in a standard format, suitable for automated analysis and display at a secure, password-protected, independent website providing rapid practice audit feedback to participants.

The present study indicated that practising colonoscopists were willing and able to undertake practice audit using a flexible, low-cost, platform-independent methodology. The data do not constitute an outcomes registry such as the Clinical Outcomes Research Initiative (19) or an epidemiological study - the case mix depends on the participating physicians and there is no independent data verification. However, the validity of the data is supported by the finding that the results were broadly similar to those of a previous national program
(13) and by the finding that shorter withdrawal times are associated with lower polyp removal rates $(8,9)$.

Although practice audit enables quality improvement and continuing professional development, it does pose challenges. If participants accept that their performance (eg, cecal intubation rates) is suboptimal, it is not clear who should provide, fund or evaluate their remediation. If, on the other hand, participants do not accept that their outcomes (eg, ileal intubation, mucosal biopsy and polypectomy rates) are inappropriate (21-23), it is not clear who should set the appropriate standards.

Overall, performance in the present audit appeared acceptable but some individuals' performance indicators fell below the norm. Practice audit enables these individuals to confidentially identify their own needs and to seek remedies without stigma. Practice audit also documents systematic differences in practice differences, for example, with respect to ileal intubation or sedation (13). These needs assessments for individuals and national groups provide a basis for the development of targeted education programs and national guidelines.

\section{CONCLUSION}

Point-of-care, peer-comparator colonoscopy practice audit is suitable for other areas of practice (eg, Barrett's esophagus or IBD) and for other health care professionals in different practice settings. In the future, other information technology systems may improve on the current methodology but, for the present, this approach provides a standard, widely available platform to collect and analyze practice audit data using existing technology at a relatively low cost, with minimal reliance on local legacy institutional technology and resources.

ACKNOWLEDGEMENTS: The authors acknowledge Joanne Cabrera RN for her participation in the QiG-E steering committee and the Canadian Association of Gastroenterology for its continued support of the practice audit program.

\section{CAPSULE SUMMARY}

What is already known about this topic:

- Published quality indicators provide measurable end points for documenting high-quality colonoscopy.

- Practice audit permits the evaluation of clinical practice to facilitate improvements in clinical care.

- Point-of-care practice audit has been used to document intraindividual and interindividual variations in endoscopy practice.

What the present study adds to our knowledge:

- Real-time, point of care, multicentre practice audit using a smartphone documents variations in colonoscopy practice without the need for complex, institution-level databases.

- Despite guidelines, more than one in three colonoscopists reported mean withdrawal times that were shorter than recommended.

- There are marked variations in colonoscopy practice, consistent with those observed in previous national practice audits.

- Real-time practice audit, with prompt, confidential, access to outcome data and targeted educational programs provides a basis for national quality improvement programs in colonoscopy practice. 


\section{REFERENCES}

1. American Society for Gastrointestinal Endoscopy. ASGE Endoscopy Unit Recognition Program. < http://www.asge.org/ ITTIndex.aspx id $=6254>$ (Accessed on November 29, 2010).

2. Joint Advisory Group on Gastrointestinal Endoscopy (JAG). The Global Rating Scale. <http://www.grs.nhs.uk/> (Accessed on November 29, 2010).

3. Rabeneck L, Rumble RB, Axler J, et al. Cancer Care Ontario Colonoscopy Standards: Standards and evidentiary base. Can J Gastroenterol 2007;21(Suppl D):5D-24D.

4. Faigel DO, Cotton PB. The London OMED position statement for credentialing and quality assurance in digestive endoscopy. Endoscopy 2009;41:1069-74.

5. Rex DK, Petrini JL, Baron TH, et al. Quality indicators for colonoscopy. Gastrointest Endosc 2006;63:S16-S28.

Am J Gastroenterol 2006;101:873-85.

6. Romagnuolo J, Enns R, Ponich T, Springer J, Armstrong D, Barkun AN. Canadian credentialing guidelines for colonoscopy. Can J Gastroenterol 2008;22:17-22.

7. Rex DK, Bond JH, Winawer S, et al. Quality in the technical performance of colonoscopy and the continuous quality improvement process for colonoscopy: Recommendations of the U.S. Multi-Society Task Force on Colorectal Cancer. Am J Gastroenterol 2002;97:1296-308.

8. Barclay RL, Vicari JJ, Doughty AS, et al. Colonoscopic withdrawal times and adenoma detection during screening colonoscopy. N Engl J Med 2006;355:2533-41.

9. Barclay RL, Vicari JJ, Greenlaw RL. Effect of a time-dependent colonoscopic withdrawal protocol on adenoma detection during screening colonoscopy. Clin Gastroenterol Hepatol 2008;6:1091-8.

10. Harewood GC, Sharma VK, de Garmo P. Impact of colonoscopy preparation quality on detection of suspected colonic neoplasia. Gastrointest Endosc 2003;58:76-9.

11. Froehlich F, Wietlisbach V, Gonvers JJ, et al. Impact of colonic cleansing on quality and diagnostic yield of colonoscopy: The European Panel of Appropriateness of Gastrointestinal Endoscopy European Multicenter Study. Gastrointest Endosc 2005;61:378-84.
12. Armstrong D, Enns R, Ponich T, Springer J, Romagnuolo J, Barkun AN. Canadian credentialing guidelines for endoscopic privileges: An overview. Can J Gastroenterol 2007;21:797-801.

13. Armstrong D, Hollingworth R, Gardiner T, et al. Practice audit in gastroenterology (PAGE) program: Qualitative study of a novel approach to continuing professional development. Can J Gastroenterol 2006;20:405-10.

14. Armstrong D, Barkun ANG, Chen Y, et al. Access to specialist gastroenterology care in Canada: The Practice Audit in Gastroenterology (PAGE) Wait Times Program. Can J Gastroenterol 2008;22:155-60.

15. Leddin D, Armstrong D, Barkun ANG, et al. Access to specialist gastroenterology care in Canada: Comparison of wait times and consensus targets. Can J Gastroenterol 2008;22:161-7.

16. CAG Practice Audit website. <http://cag.medicalconsensus.org> (Accessed on May 5, 2010).

17. Rostom A, Jolicoeur E. Validation of a new scale for the assessment of bowel preparation quality. Gastrointest Endosc 2004;59:482-6. (Erratum in Gastrointest Endosc 2004;60:326).

18. Moayyedi P, Tepper J, Hilsden R, Rabeneck L. International comparisons of manpower in gastroenterology. Am J Gastroenterol 2007;102:478-81.

19. Lieberman D, de Garmo P, Fleischer D, Eisen G, Helfand M. Patterns of endoscopy use in the United States. Gastroenterology 2000;118:619-24.

20. Ko CW, Riffle S, Michaels L, et al. Serious complications within 30 days of screening and surveillance colonoscopy are uncommon. Clin Gastroenterol Hepatol 2009;8:166-73.

21. Harewood GC, Mattek NC, Holub JL, Peters D, Lieberman DA. Variation in practice of ileal intubation among diverse endoscopy settings: Results from a national endoscopic database. Aliment Pharmacol Ther 2005;22:571-8.

22. Harewood GC, Olson JS, Mattek NC, Holub JL, Lieberman DA. Colonic biopsy practice for evaluation of diarrhea in patients with normal endoscopic findings: Results from a national endoscopic database. Gastrointest Endosc 2005;61:371-5.

23. Lieberman DA, Holub JL, Moravec MD, Eisen GM, Peters D, Morris CD. Prevalence of colon polyps detected by colonoscopy screening in asymptomatic black and white patients. JAMA 2008;300:1417-22. 


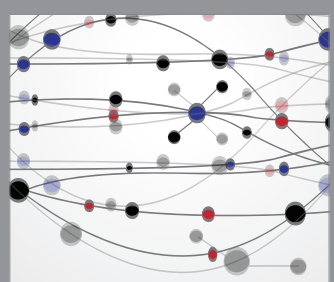

The Scientific World Journal
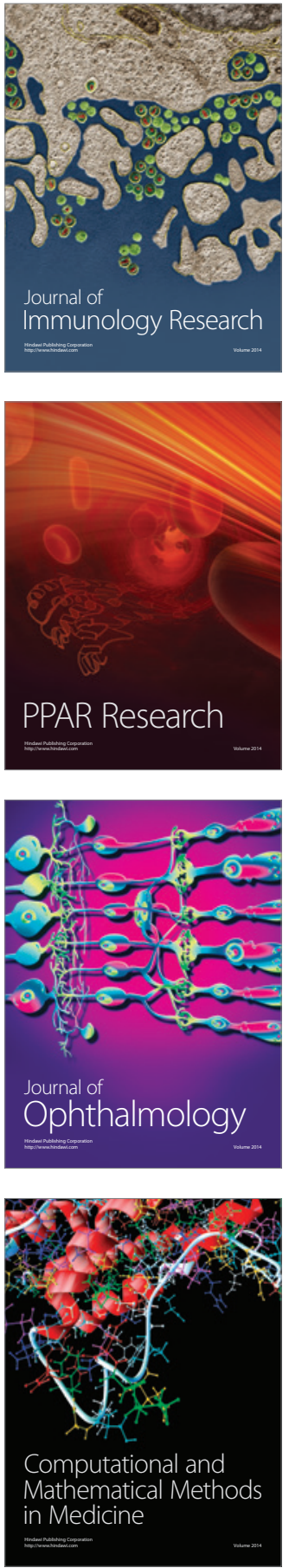

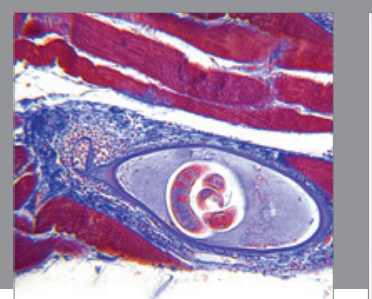

Gastroenterology Research and Practice

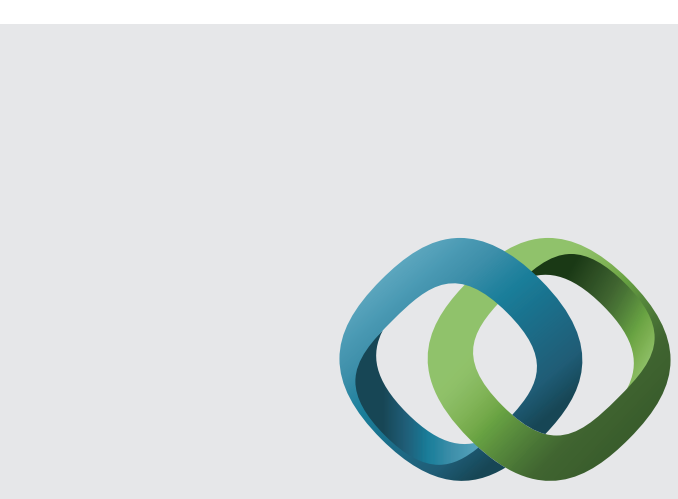

\section{Hindawi}

Submit your manuscripts at

http://www.hindawi.com
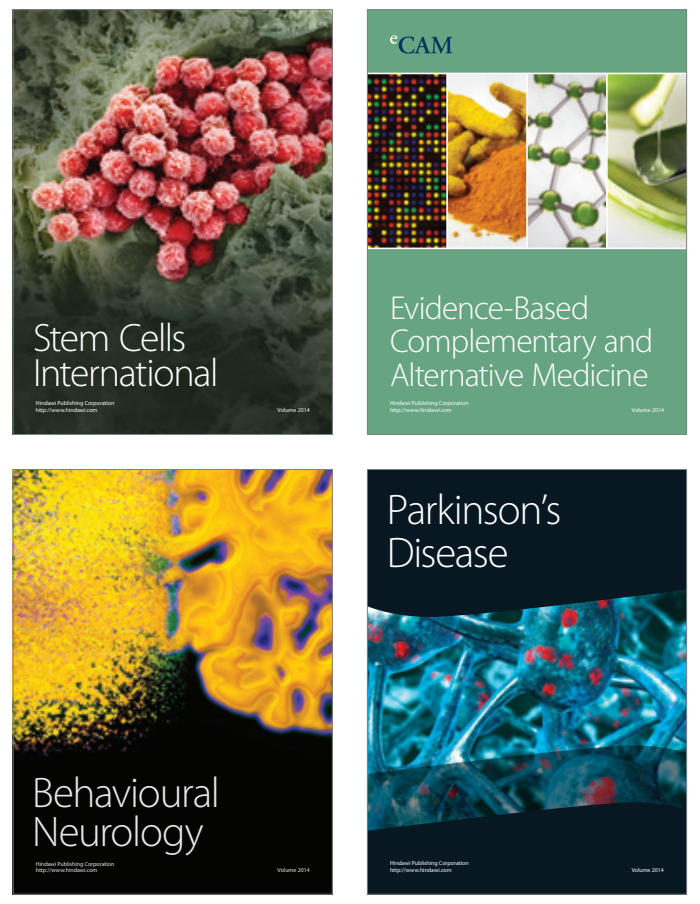
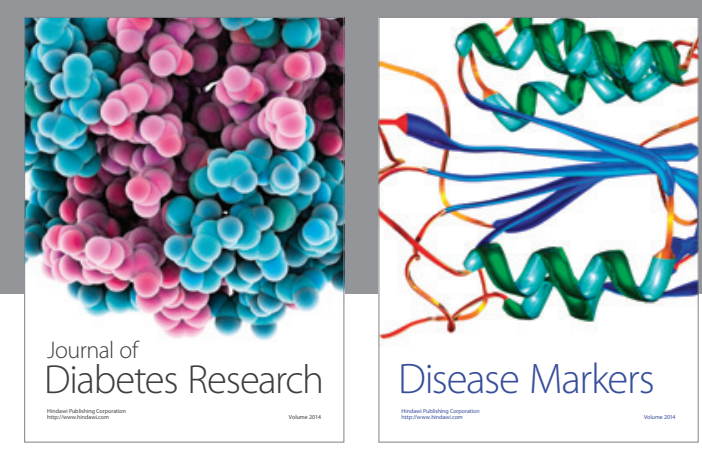

Disease Markers
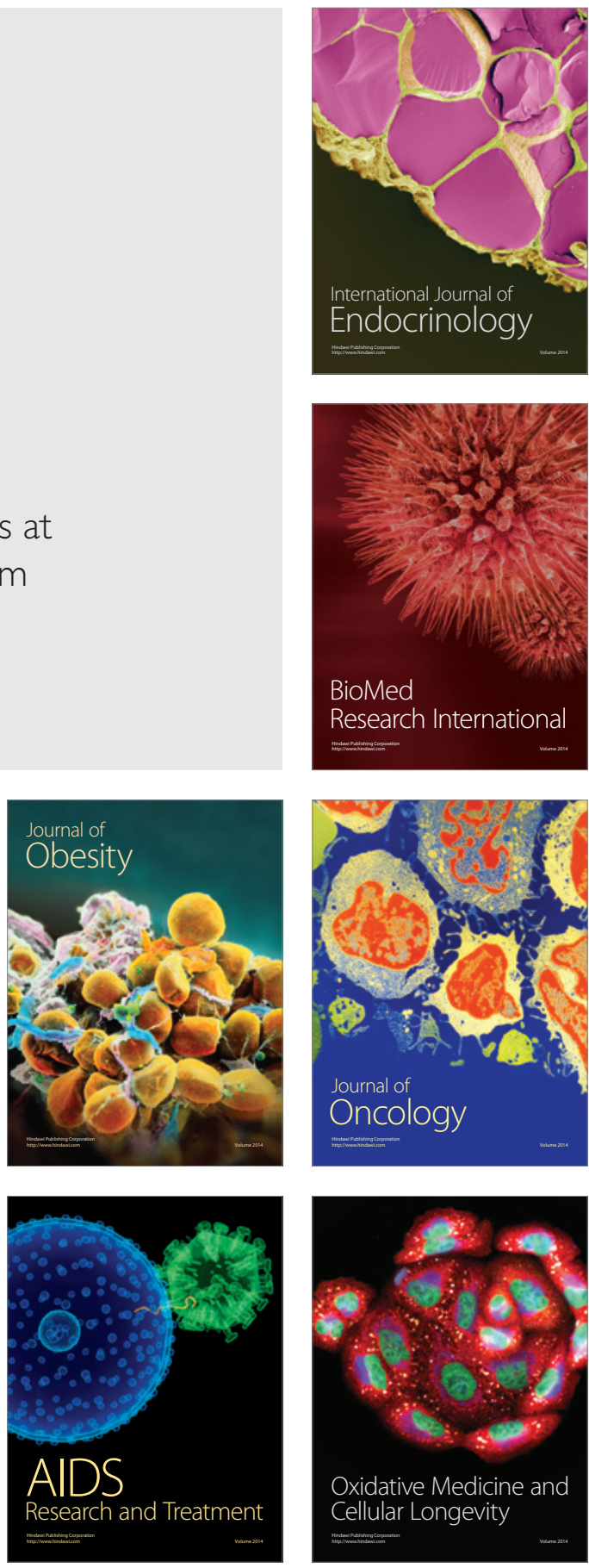